Rev. Hist., $N^{\circ} 26$, vol. 2, Julio-Diciembre 2019: 5 - 32

ISSN 0717-8832

\title{
Minería, crisis económicas y flujos migratorios en Atacama meridional: Taltal (Chile), 1870-1950*
}

\author{
Mining, economic crises and migratory flows in southern Atacama: Taltal (Chile), \\ 1870-1950.
}

\author{
Milton Godoy Orellana**
}

\begin{abstract}
RESUMEN
El artículo estudia la relación existente entre las crisis económicas y los flujos migratorios en Taltal y su hinterland en el periodo de auge y decadencia de la producción minera en el distrito. El énfasis está puesto en las crisis económicas de la década del veinte del siglo pasado y su impacto en la industria salitrera, especialmente en la crisis de 1929, mediante el análisis de la población en sus dimensiones interregionales e intrarregionales, bajo la hipótesis de que este periodo fue terminal, significando la merma poblacional del departamento de Taltal, el despoblamiento de la pampa y el cierre o desmantelamiento de 13 oficinas después de 1930, quedando en funcionamiento 3 a 4 de forma esporádica y grandes interrupciones, que implicó la venta y posterior desmantelamiento paulatino de la extensa red de The Taltal Railway Company.
\end{abstract}

Palabras clave: salitre, crisis económicas, migración, Taltal

\section{ABSTRACT}

The article examines the relationship between economic crises and migratory flows in Taltal and its hinterland in the period of boom and bust in mining production in the district. Emphasis is placed on the economic crises of the 1920s and their impact on the saltpetre industry, especially in the 1929 crisis, by analysing the population in its interregional and intraregional dimensions, under the hypothesis that this period was terminal, meaning the population decline of the department of Taltal, the depopulation of the pampa and the closure or dismantling of 13 offices after 1930, remaining in operation 3 to 4 of sporadic form and great interruptions, that implied the sale and later gradual dismantling of the extensive network of The Taltal Railway Company.

Keywords: saltpeter, economic crisis, migration, Taltal

Recibido: junio 2019

Aceptado: noviembre 2019

\footnotetext{
* Este artículo es resultado del Proyecto Fondecyt N 1170738. Investigador Asociado Universidad de Tarapacá. Mis agradecimientos al aporte y comentarios de Carolina Valenzuela, Marco Murua y Roberto Figueroa.

** Doctor en Historia. Universidad de Chile, Email: mgodoyorellana@gmail.com
} 
Había que irse sin mirar atrás. En el caso de paralización de faenas, los campamentos eran desarmados, desmontados y encajonados, y los materiales sobrantes vendidos por chatarra. Sus habitantes nunca más volvían a sus casas, sus calles, el pueblo donde crecieron, se casaron, tuvieron hijos y enterraron a sus muertos. por eso había que irse sin voltear la cabeza: nos podía pasar lo que a la mujer de Lot. Hernán Rivera Letelier, La autodidacta. Agosto, 2019.

Statistics are like a drunk with a lamppost: used more for support than illumination Winston Churchill (1874-1965)

\section{Introducción}

Los primeros días del mes de diciembre de 1909, Luis Le Meunier, escribía desde alguna abandonada habitación del puerto de Taltal a su hermano Wenceslao, quien trabajaba para la empresa Lautaro Nitrate Company en la pampa. A la sazón, Luis, un desempleado más, le comunicaba a su hermano que "sufro mucho por quie la comía es mui poca i ai quie comprar pan, azúcar, té, y los que no tenimos plata aguantamos las ganas de comer [sic]"1 . Luis, al igual que decenas de desempleados enfrentaba los embates de uno de los tantos periodos de contracción económica que episódicamente golpeaba a los trabajadores en la pampa salitrera. Su carta permaneció archivada por más de cien años. Aun, sin conocer la respuesta, es dable suponer que esta no cambiaría la realidad de los hermanos Le Meunier, uno continuaría sobreviviendo en la pampa hasta el próximo despido y el otro definiría su propia suerte en el puerto.

El estudio historiográfico del mundo social de la minería chilena, durante gran parte del siglo $X X$, es una realidad que golpea desde sus fuentes. Más allá de alguna historiografía que recrea la novela rosa, de la pampa, asentando una construcción narrativa melosa y alambicada que añora un mundo perdido - un verdadero locus amoenus- de sociabilidades populares solidarias, plagada de momentos de jolgorio y algunos de cine, música o fiesta, la realidad fue brutal.

El trabajo en las oficinas salitreras era una realidad extrema en su geografía, marcada por la existencia de oficinas y poblados insulares en el desierto - “la Siberia caliente" ${ }^{2}$ como le llamaban los obreros- verdaderos oasis capitalistas, que configuraban sociedades duales, social y económicamente, que transitaban entre la abundancia y carencia, donde coexistían los administradores y sus familias, quienes contaban con las mayores comodidades posibles y el espacio de los obreros expuestos al reverso de esa realidad. El conjunto de los habitantes se

\footnotetext{
1 “Luis Le Meunier a su hermano Wenceslao". Taltal, 3 de diciembre de 1909. Archivo Histórico Universidad Católica del Norte, Fondo Lautaro Nitrate Company, Caja $\mathrm{N}^{\circ} 3$, s/f. (en adelante AHUCN)

2 BN, La Voz del Obrero. Taltal, 21 de abril de 1908.
} 
enfrentaba a tempestuosos cambios definidos por los vaivenes del nitrato en los mercados de los centros urbanos de las economías europeas, que en aquellos años marcaban las directrices del capitalismo.

El asunto resultaba simple: las empresas salitreras captaban mano de obra cuando la demanda y los precios del salitre estaban en su apogeo y los despedían frente a las oscilaciones o crisis económicas. Para suplir la demanda de trabajadores existía un sistema de captación en los poblados del centro y sur del país denominado enganche, que proveía de obreros a las oficinas salitreras. Este mecanismo permitía disponer de un importante número de trabajadores que podían suplir la demanda ocasional o reemplazar a quienes participaban en huelgas o protestas debido a las adversas condiciones laborales existentes. Frente a la huelga o la crisis, simplemente, se aplicaba el despido.

En las crisis de las últimas décadas del siglo XIX y la primera mitad del siglo XX esta fue una condicionante. Los trabajadores, ayer ensalzados como creadores de riqueza, al ser despedidos, devenían en parias del capitalismo y un peligro para el orden y seguridad del puerto. Como escribió una autoridad de Copiapó a mediados del siglo XIX, que "no haya misericordia con esta clase de gente: o que trabajen o que abandonen un pueblo, que sino trabajan [...] tienen que robar" $^{3}$. Décadas después, la valoración de los trabajadores no había cambiado sustancialmente. Despedidos de una faena minera, la mayoría eran obligados, por las circunstancias o las autoridades, a desplazarse hacia los poblados del Norte Chico o Chile Central y los extranjeros de países vecinos a alguna ciudad fronteriza.

En el periodo, el tratamiento a los despedidos fue similar, sin diferenciar chilenos y extranjeros. Las acciones realizadas para solucionar el problema respondían a una matriz conductual resultante de la superposición de intereses de empresarios y agentes estatales. Probablemente, los prolegómenos de estas prácticas se encuentran en la crisis local que provocó el impuesto al salitre en 1882, cuando se iniciaron las primeras acciones aplicadas en casos de cierre de oficinas salitreras ${ }^{4}$.

Aunque esta fue una práctica permanente en las crisis episódicas enfrentadas en la región ha persistido el considerar que los despidos masivos y traslados de pobladores al centro y sur del país fue el resultado, exclusivamente, de la crisis económica de 1929, cuyo impacto, además, habría gatillado el proceso de despoblamiento de la pampa salitrera. Sin duda, esa fue una crisis terminal para varias provincias de la región salitrera y las secuelas se hicieron visibles en sus pampas y puertos, aunque los efectos fueron diferenciados entre una y otras zonas.

\footnotetext{
${ }^{3}$ BN, El Pueblo. Copiapó, 28 de septiembre de 1852.

${ }^{4}$ Godoy O., Milton. La puerta del desierto: Estado y región en Atacama Taltal, 1850-1900. Ed. Mutante - Universidad de Tarapacá - LIA Mines, CNRS. Santiago, 2018.
} 
Considerando un periodo más amplio de tiempo, a saber, la primera mitad del siglo XX, es posible proponer como hipótesis que el despoblamiento de la pampa salitrera fue un proceso largo. En este hubo variables intercensales, movimientos poblacionales intrarregionales e interregionales, en que la expulsión y captación de mano de obra funcionó como un mecanismo regulador del flujo de trabajadores, en ocasiones, independiente de las crisis económicas, aunque acentuados por estas.

La idea central es analizar la relación entre explotaciones mineras, crisis y poblamiento en la región de Taltal y su hinterland. El proceso se estudia en los años anteriores a 1930, analizando la expulsión y captación de trabajadores debido a las crisis y los despidos masivos, entre estos se consideran los trust establecidos por los empresarios para controlar la oferta, mediante la reducción de la producción a montos determinados, limitando los máximos de la capacidad instalada de cada salitrera. Al completar su cuota se detenían las faenas y se procedía al despido de los trabajadores y cuando era necesario reanudar la producción se procedía a realizar nuevos contratos ${ }^{5}$. Otro mecanismo, no siempre ligado a las crisis económicas y que incidía notablemente en la mano de obra fue la huelga y los consecuentes despidos masivos a los involucrados o, en su defecto, la declaración de un lockout empresarial, que detenía toda la actividad.

Por tanto, la movilidad de los trabajadores es un tema que cruza las realidades productivas de diversas regiones extractivas, a nivel mundial. Recientemente, se editó un conjunto de tres estudios de autobiografías inéditas, afortunados hallazgos, de otros tantos obreros ingleses que muestran la vida, aventuras, recorridos y supervivencia de obreros ingleses trasladados a Francia y Alemania. Precisamente, esta publicación connota que la modernización capitalista e industrialización, conlleva desplazamientos de trabajadores, en este caso británicos, a los más diversos destinos del mundo en busca de una vida mejor ${ }^{6}$, ejemplificando la alta movilidad en el periodo.

Uno de estos destinos fue las pampas salitreras en el desierto de Atacama, donde confluyeron trabajadores provenientes de diversos países del mundo y, esencialmente, mano de obra desde el Norte chico y el centro - sur de Chile. Estas migraciones laborales adquirieron diferentes formas. Podían ser voluntarias, individuales o familiares y manejadas por los trabajadores en su libre albedrío; o contratados y movilizados por las propias empresas o sus representantes de manera engañosa. Para el efecto, mediaba un contrato conocido como

\footnotetext{
${ }^{5}$ Monteon Michael. "The Enganche in the Chilean Nitrate Sector, 1880-1930", Latin American Perspectives, Vol. 6, №. 3,1979 , p. 68.

${ }^{6}$ Bensimon Fabrice. 2017. Les sentiers de l'ouvrier. Paris, Ed. de la Sorbonne, pp. 5-21. Ver del mismo autor "British workers in France, 1815-1848", Past and Present, 213, Oxford, 2011, pp. 147-189.
} 
indenture o engagement ${ }^{7}$, una variante, en el caso de la región estudiada, a través del reclutamiento con pequeños adelantos monetarios y estímulos entregados por individuos al servicio de una oficina salitrera -“enganchados", en el decir de la pampa- para trasladarse a la zona de explotación.

La ingente afluencia de trabajadores y sus familias convirtió el desierto en una tierra de migrantes, poblado por personas que abandonaron sus lugares de origen en busca de mejores condiciones de vida. Como escribió Vera Zamagni, el migrante es móvil por definición "y considera normal ir en busca de trabajo donde lo haya, en lugar de quedarse pasando hambre donde ha nacido" ${ }^{8}$, acudiendo en masa donde se demandaba fuerza de trabajo y se prometían mejores condiciones de vida. Este escenario, en Chile, fue el desierto de Atacama, región que enfrentaba un importante ciclo económico, principalmente, por la producción de nitrato en las denominadas oficinas salitreras, espacios urbanos complejos donde vivían los obreros y sus familias.

\section{Historiografía reciente de la sociedad y el ciclo salitrero}

En la última década se han publicado algunos nuevos trabajos acerca de la minería del nitrato. Sin intentar una profunda síntesis analítica de sus orientaciones, en el periodo han existido importantes proyectos de investigación que han ampliado la cobertura espacial y temática de la actividad y la región que fue escenario de este ciclo extractivo. El principal aporte de conjunto fue realizado en el libro $L a$ sociedad del salitre ${ }^{9}$, que contiene una discusión global de la sociedad configurada en torno a la producción de nitrato, intentando contribuir al conocimiento de las más diversas expresiones de su modus vivendi. El escenario de estos trabajos lo constituye el territorio entre Pisagua y Taltal, considerando sus más diversos actores, a saber, pioneros, baqueanos, empresarios, trabajadores, en sus más complejas relaciones políticas, sociales y económicas.

En este mismo periodo, surgieron nuevas investigaciones que enriquecen las miradas temáticas acerca del ciclo del salitre analizando las políticas estatales y territoriales ${ }^{10}$, la vida de

\footnotetext{
7 Guerassimoff, Eric e Issiaka Mandé. 2015. Le travail colonial. Engagés et autres mains - d'oeuvre migrantes dans les empires, 1850 - 1950. Paris, Ed. Riveneuve; ver también Moulier-Boutang, Yann. 2006. De la esclavitud al trabajo asalariado. Economía histórica del trabajo asalariado embridado. Madrid, Ed. Akal, p. 907.

${ }^{8}$ Zamagni Vera. 2011. Historia Económica de la Europa contemporánea. Barcelona, Ed. Crítica, p. 93.

${ }^{9}$ González M., Sergio. 2013. La Sociedad del Salitre, Protagonistas, migraciones, cultura urbana y espacios públicos 1870-1940. Santiago, Ril Editores.

${ }^{10}$ Artaza B., Pablo. “'Los cantones salitreros como espacio de tránsito y circulación. Tarapacá durante el ciclo de expansión del salitre". Revista Chilena de Antropología, 37/1, Santiago, 2018, pp.: 164-182; Godoy O., Milton. "Configuración estatal y económico-social de un espacio productivo minero en Chile: Taltal, 1870-1930", Estudios Atacameños, N 62, San Pedro de Atacama, 2019; Richard, Nicolas y Hernández, Consuelo. "Las alambradas en la Puna de Atacama: alambre, desierto y capitalismo". Revista Chilena de Antropología, N³7, Santiago, 2018, pp. 83107; Donoso R., Carlos. "Los albores de la industria salitrera en Tarapacá". Chungará, vol.50/3, Arica, 2018, p.459-
} 
los habitantes de la pampa, sus condiciones laborales, organización política ${ }^{11}$, la participación de mujeres en el ciclo salitrero ${ }^{12}$, y la presencia de extranjeros e indígenas ${ }^{13}$. En el conjunto de estos trabajos, al igual que en la tradición historiográfica que le antecede, existe una suerte de convicción en el periodo de quiebre de este ciclo y las repercusiones sociales en los pobladores de la pampa y el proceso de repliegue del ecúmene del desierto hasta su despoblamiento.

No obstante, una reciente investigación cuestiona lo que denomina la "narrativa apocalíptica", sustentada en una supuesta suma de errores cometidos por los historiadores que han trabajado el tema, al afirmar que esta fue "una migración masiva (permanente) desde los distritos de nitratos". Contrario sensu, la investigación discutida plantea una nueva hipótesis estableciendo "que la producción se mantuvo en niveles respetables a pesar de la crisis, este factor no pudo haber precipitado una migración masiva y permanente desde los distritos de nitratos, como se ha mantenido anteriormente" ${ }^{14}$. La propuesta establece que no se ha intentado "cuantificar este fenómeno a nivel de cantón de nitratos", asunto que probaría lo falaz de las afirmaciones de una corriente historiográfica que construyó la citada "narrativa

470; González M., Sergio; Calderón G., Renato y Artaza B., Pablo. “El fin del ciclo de expansión del salitre en Chile: la inflexión de 1919 como crisis estructural”. Revista de Historia Industrial, Vol. 25, № 65, Barcelona, 2016. Godoy O., Milton. "Los prolegómenos de una crisis episódica: El cantón de Taltal y la ley de impuesto a la producción salitrera, 1873-1883". Historia, vol. 2, Santiago, 2016, pp. 455-486; Donoso R., Carlos. "El ocaso de la dependencia salitrera (1914-1926)". Diálogo Andino, № 45, Arica, 2014, pp. 97-118; del mismo autor "Nacionalizar el salitre: debates iniciales sobre el control fiscal de la industria (Chile, 1880-1916)". Chungará, vol.46/1, Arica, 2014, pp.115-130.

11 Artaza B., Pablo. 2016. "El reverso del bienestar. La creación del departamento de bienestar social y el reforzamiento del control social en el norte grande a principios de los años 20". Estudios Atacameños, $\mathrm{N}^{\circ} 52$, San Pedro de Atacama, p.49-68; González M., Sergio y Artaza B., Pablo.2015. "Cateando la palabra: la construcción de nuevos archivos sobre la sociedad del salitre". Diálogo Andino, N 46, Arica, pp. 55-70; Artaza B., Pablo. 2015. "De lo social a lo político en el movimiento social.

12 Kalazich, Fernanda. 2018. "Para estudiar la prostitución en las pampas salitreras. Apuntes desde los estudios subalternos y la arqueología industrial”. Revista Chilena Antropología, №37, Santiago, pp. 131-142; González, José; Lufin Varas, Marcelo y Galeno Ibaceta, Claudio.2017."Mujeres latinoamericanas en el mercado laboral de Antofagasta durante el ciclo salitrero, 1880-1930". Estudios atacameños, №54, San Pedro de Atacama, pp. 153-178; Carrasco, Ana M. 2014. "Remolinos de la pampa. Industria salitrera y movimientos de mujeres (1910-1930)". Estudios atacameños, $\mathrm{N}^{\circ} .48$, San Pedro de Atacama, p.157-174.

13 Galaz-Mandakovic, Damir. 2018. “De Guggenheim a Ponce. Sistema técnico, capitalismo y familias en el extenso ciclo de los nitratos en El Toco y Tocopilla (1924-2015)". Revista Chilena de Antropología, N³7, Santiago, pp. 108130; González M., Sergio. 2018. "Las primeras estacas del reino salitrero de John Thomas North. El origen del mito". Cuadernos de Historia, № 49, Santiago, pp.7-36; González, José A. 2018. "La Compañía de Salitres de Antofagasta, Chile. El desafío de su modernización empresarial e innovación estratégica”. Estudios Atacameños, N.60, San Pedro de Atacama, pp.133-159; González; Lufin, Varas, y Galeno. 2014. "La presencia boliviana en el desierto de Atacama...", pp. 109-126; de los mismos autores "Británicos en la región de Antofagasta. Los negocios concomitantes con la minería del desierto de atacama y sus redes sociales (1880-1930)". Estudios atacameños, № 48, San Pedro de Atacama; González M., Sergio. 2009. "La presencia boliviana en la sociedad del salitre y la nueva definición de la frontera: auge y caída de una dinámica transfronteriza (Tarapacá 1880-1930)". Chungará, vol.41/1, Arica,pp.71-81

${ }^{14}$ Rivero, Rodrigo; Navarrete, Juan; Órdenes, Cristian y Llorca, Manuel. 2019. "The Demographic Consequences of the End of Chile's Nitrate Boom, c.1907-1940" Bulletin of Latin American Research, Society for Latin American Studies, vol. 37, Reino Unido, p. 2. 
apocalíptica". Para el caso particular del distrito minero de Taltal -que corresponde territorialmente con la comuna- el estudio de la producción, el transporte y los habitantes denotan que esta pretensión es absolutamente equivoca. En efecto, el análisis de las variables indicadas esclarece que las crisis de la década del veinte provocaron movimientos masivos y que la de 1929 fue determinante en la producción de nitrato y en los movimientos de población en Taltal y su hinterland.

No bastando con aquello, la propuesta en cuestión incurre en, a lo menos, tres errores esenciales. En primer lugar, se entiende el cantón como "concentraciones de personas que surgieron alrededor de los campos de nitrato. No se clasificaron como divisiones administrativas o políticas del gobierno central, pero su ubicación geográfica puede establecerse claramente. Espontáneamente, la gente empezó a hablar de estas concentraciones como cantones, y les dio nombres" ${ }^{15}$. Desde la perspectiva del análisis espacial no se puede confundir las dimensiones del espacio extractivo informal y de uso popular, denominado cantón, que resulta insulso al considerar la división político-administrativa en que se basaban los censos. ¿Cuáles fueron las dimensiones territoriales del "cantón Taltal"? Se desconocen. Solo se sabe que incluye un determinado conjunto de salitreras ¿y las placillas mineras, las explotaciones dispersas o los pueblos de servicio, estaciones y posadas? El cantón, probablemente, era un resabio de la distribución administrativa usada en el periodo boliviano -según el decreto de 1826, cantón era la subdivisión de una provincia, que poseía una junta municipal ${ }^{16}$ - y que se hizo extensiva desde Antofagasta a los demás espacios de explotación salitrera. Considerando lo anterior, el cantón se comprende como un espacio de explotación interrelacionado, configurado por un conjunto de oficinas salitreras, pueblos de servicio, unidos por una red caminera y ferroviaria -en la región era The Taltal Railway Company Limited-que conexaba estos nodos en una red dendrítica cuyo punto principal era el puerto que conectaba con los mercados internacionales para la exportación de materias primas e importación de bienes para el sustento de las explotaciones salitreras del interior ${ }^{17}$. Esta especificidad con relación a los puntos de producción de nitrato, no acaba con la realidad regional, principalmente, porque Taltal tuvo importantes centros productivos de oro, plata y cobre, donde destacaron las Placillas de Cachinal de La Sierra, Esmeralda y de Aguada de Cachinal ${ }^{18}$.

\footnotetext{
${ }^{15}$ Ibíd., pp. 2-3

${ }^{16}$ Galindo de Ugarte.1991, Marcelo. Constituciones bolivianas comparadas, 1826-1967, La Paz, Ed. Los Amigos del Libro, p. 583.

${ }^{17}$ Godoy O., Milton. "Configuración estatal...”; Artaza, Pablo. “'Los cantones salitreros...”, González, Sergio y Artaza, Pablo. "El concepto de cantón salitrero...", en González, Sergio. La sociedad del salitre... p. 331.

${ }^{18}$ Godoy O., Milton. 2015. "Las placillas del desierto. Construcción de espacio urbano en el despoblado de Atacama. Bolivia y Chile, 1870-1900". Amérique Latine Histoire et Mémoire. Les Cahiers ALHIM, 29, Paris, URL : http://alhim. revues.org/5183
} 
En este mismo sentido el cantón supone una dimensionalidad territorial inexacta e indefinida, que se complementó con las redes generadas allende Los Andes, puntualmente con el noroeste argentino, de donde provenía el ganado ovino y los mulares; y desde 1913, con el sur y norte del país en la Estación Santa Catalina, mediante el tren longitudinal.

El corolario de lo anterior, es que los censos operan sobre la base de la conceptualidad territorial establecida por el aparato estatal y que en el periodo se constituía en el departamento de Taltal, reorganizado a partir de la distribución de 1884, cuyo territorio estaba formado por las comunas de Taltal y Catalina y fue organizado mediante el Decreto con Fuerza de Ley N.o 8.583 del 30 de diciembre de 1927 (ver mapa 1). La Comuna de Taltal comprendía las subdelegaciones $1^{\circ}$ y $2^{\circ}$ de Taltal, $3^{\circ}$ Esmeralda y $5^{\circ}$ Paposo. Mientras que Catalina la componían las Subdelegaciones $4^{\circ}$ Santa Luisa, $6^{\circ}$ Refresco, $7^{\circ}$ Cachinal, $8^{\circ}$ Vaquillas y $9^{\circ} \mathrm{El}$ Guanaco $^{19}$, esta última constituida, en 1887 , a partir del segundo distrito de Cachinal ${ }^{20}$. Esta comuna de Catalina, fue eliminada mediante el Decreto Ley N. 02.868 del 26 de octubre de 1979, que establecía la regionalización que impulsó la dictadura del periodo.

El segundo error en la metodología aplicada es que no considera los periodos intercensales. En efecto, en una perspectiva de larga duración, este proceso presentó diferentes intensidades ligadas a los vaivenes de la economía y a la irrupción de los fertilizantes químicos en los mercados internacionales. Estas inestabilidades, no se expresaron en los censos, puesto que eran variaciones regulares de expulsión y captación de mano de obra.

El tercer problema, es que tampoco se consideraron las variaciones intrarregionales que no se visibilizan en la lectura de la población provincial, sino que se presentan en movimientos internos, entre las comunas de la pampa, donde se ubican las salitreras y el puerto. Esta perspectiva permite enfrentar con mayor claridad el despueble de la zona salitrera y el repliegue de la población a los puertos.

\section{Flujo y reflujo capitalista en el desierto}

En su clásico artículo acerca del trabajo decimonónico, Eric Hobsbawm, escribió que "la historia del siglo XIX es una historia de movimiento y migración" ${ }^{21}$. En Chile, esta afirmación es valedera desde, aproximadamente la cuarta década del siglo XIX, persistiendo hasta mediados del siglo $X X$. Lo anterior, no significa desconocer los desplazamientos de mano de obra en el periodo de

\footnotetext{
${ }^{19}$ Decreto con Fuerza de Ley 8583. Santiago, 30 de diciembre de 1927. www.leychile.cl/N?i=19463\&f=1928-02$01 \& p=$

${ }^{20}$ Boletín de las leyes y decretos de Chile, Vol. 54, Santiago, Imp. Nacional, 1887, p. 880. Ver también Godoy 0., Milton. "Llamado a un fabuloso porvenir. Explotaciones auríferas y poblamiento en el desierto de Atacama: El mineral de El Guanaco y la placilla de Aguada de Cachinal, 1880-1930". Cuadernos de Historia, № 51, Santiago, 2019.

${ }^{21}$ Hobsbawm, Eric. 1951. "The tramping artisan", The Economic History Review, New Series, Vol. 3, №. 3 (CIUDAD), pp. 299. Ver tambien Bensimon, Fabrice. 2011."British Workers in France, 1815-1848" Past \& Present, Vol. 213/1, Oxford, pp. 147-189.
} 
Chile colonial, ya sea mediante la reubicación de indígenas encomendados o por las acciones individuales de los peones sin adscripción, ni domicilio fijo. El problema de fondo es un asunto de intensidades y magnitudes existentes entre ambos periodos.

La idea es destacar que el proceso migratorio de larga duración, tuvo tres fases que se sucedieron en el norte minero de Chile. Primero, hubo un importante desplazamiento poblacional a las tierras del Norte Chico, en el contexto del denominado ciclo cuproargentífero (1840-1880), cuando ingentes masas de trabajadores se desplazaron al norte del país tras la demanda de mano de obra de las minas, principalmente, de cobre, plata y oro; luego, hubo un rebasamiento de los límites, en términos de extracción minera, en que se había convertido el sector septentrional de la provincia de Atacama, creada en 1843. Este ciclo asentó población en las provincias de Atacama y Coquimbo, hasta que se inició un paulatino proceso de despoblamiento de centros mineros cupríferos y argentíferos, debido a las oscilaciones económicas que provocaba la minería. Esta fue la crisis de 1873, que marcó un hito en el periodo de expansión de la minería del cobre, cuya actividad perdió el ímpetu inicial e inició un descenso que impactó negativamente en la economía regional y en la mano de obra local. En abril de 1881, el alcalde del otrora importante puerto cuprífero de Caldera reclamaba acerca de la emigración de su población a centros "de mayor actividad, trabajo i recursos" como los puertos salitreros de Taltal, Antofagasta e Iquique, lo que hacía decrecer "palpablemente los arbitrios y especialmente los provenientes de la exportación del cobre"22.

Una segunda fase, se produjo en torno a la extracción de nitrato, en un periodo que se reconoce como el ciclo salitrero (1880-1930), que tuvo constantes traslados de trabajadores entre las diversas faenas o retornando hacia el sur debido a los despidos en las oficinas salitreras. Para el caso chileno, este proceso se inició hacia mediados del siglo XIX, con la exploración del territorio meridional del desierto de Atacama, aun no incorporado al proceso expansivo capitalista que enfrentaba el norte de Chile y que implicaría la ocupación de territorio boliviano. Partiendo desde el contiguo Norte Chico, ingentes masas de trabajadores se desplazaron al desierto para trabajar minas de cobre y plata, movimiento que se consolidó con el descubrimiento de extensas pampas salitreras, las que originaron, hacia 1870, las primeras oficinas salitreras en territorio chileno e iniciaron un incipiente proceso de poblamiento con la fundación del puerto de Taltal en 1877 que centró aquella actividad. Después de algunas inestabilidades en la producción de nitrato, principalmente, debido a las cargas impositivas, el proceso se consolidó para alcanzar su peack en las primeras décadas del siglo XX.

En tercer lugar, existió un proceso de expansión y repliegue en la ocupación de las tierras interiores del desierto, acorde con similares movimientos en la demanda salitrera. En esta fase hubo un constante flujo de población inter e intrarregional, como se puede observar en el

${ }^{22}$ Caldera, abril de 1881. ANHMININT, Vol. 780, s/f. 
gráfico $\mathrm{N}^{\circ} 1$, donde quedan claras las altas y bajas poblacionales en el periodo anterior 1930. En la región de Taltal, el proceso fue acentuado -y sin retorno- después de la crisis de 1929, que provocó otro de los grandes hitos en el proceso analizado. Desde esa fecha, una multiplicidad de factores, entre los que destaca la masificación del uso de salitre sintético y las políticas gubernamentales, se inició un proceso de despoblamiento de la región estudiada. Con avances y retrocesos el flujo poblacional negativo se mantuvo hasta mediados del siglo XX, cuando en 1952 la población -según los censos de los años correspondientes-fue menor que en 1885.

Considerando esta temporalidad, es posible establecer dos grandes hitos que enmarcan el periodo analizado. Los movimientos poblacionales alcanzan una magnitud diferente desde la crisis de 1873, año que demarca un cambio en la intensidad de los flujos migratorios, aunque no con la masividad, sincronía e impactos económicos sociales de la crisis de 1929 y sus efectos colaterales de los años siguientes, hasta 1950.

Al considerar el último cuarto del siglo XIX es posible constatar la existencia de un proceso de contracción económica, conocido como la Gran Depresión decimonónica (1873-1896), que incluía otras inestabilidades recesivas, tales como una depresión entre 1882-95; y crisis internas en 1890, 1893 y 1896. Así, es posible constatar que la triada crisis - cesantía - migración, estuvo presente durante el periodo estudiado, no exclusivamente en las fechas hitos del mismo, sino como parte de la realidad económico social de la región, siendo frecuentes las inestabilidades provocadas por estos procesos de contracción económica que se repitieron en 1914-1915, 1918-1919, 1921-1922 y 1925-1926. Finalmente, en 1929 se llegó al momento culminante del periodo que marcó una inflexión en el desarrollo regional, que, en términos globales, se superó con la segunda Guerra Mundial, pero, en la región significó el comienzo del deterioro final de la economía salitrera.

El concepto de crisis define el periodo más agudo de contracción de una economía, es el "punto de inflexión de un ciclo", marcada por el fin de una fase expansiva, de prosperidad, iniciando un proceso recesivo, con un impacto que se caracteriza por "una perturbación dramática de la sociedad"23. Más allá de constituirse en un quiebre esporádico y efímero, las crisis son recurrentes y caracterizan las economías de mercado, haciéndose normal la fragilidad financiera. John Maynard Keynes, en su Teoría General identificó dos fallas esenciales en el sistema capitalista: el desempleo crónico y la desigualdad excesiva. A estas, Hyman Minsky

\footnotetext{
${ }^{23}$ Rapoport, Mario y Brenta, Noemí. 2010. "La crisis económica mundial: ¿el desenlace de cuarenta años de inestabilidad?", Revista Problemas del Desarrollo, 163/41, Ciudad de México, p. 9; Para un conjunto de definiciones ver Reinhart, Carmen y Rogoff, Kenneth. 2011. Esta vez es distinto: ocho siglos de necedad financiera. México, Ed. FCE.
} 
agregó una tercera "la inestabilidad normal del capitalismo financiero" ${ }^{24}$. En su perspectiva teórica, las crisis se presentan de manera recurrente dentro del sistema capitalista, aunque pueden ser controladas en su impacto y gravedad, pero, no eliminadas. Además, señala que la inestabilidad e incoherencia que se muestra está relacionada "con el desarrollo de estructuras financieras frágiles que ocurren normalmente dentro de las economías capitalistas" 25 y que esta inestabilidad "está determinada por mecanismos dentro del sistema". Ergo, la economía se torna inestable por elementos intra sistémicos y no por variables externas, -señaló Minsky"sino por su naturaleza" 26 , convirtiéndola en "una característica muy arraigada de una economía capitalista" 27.

Por tanto, las crisis no deben explicarse como una anomalía, un hiato en el sistema capitalista, sino una constante, con cierta recurrencia y que obedecen a tensiones intra sistémicas “imposibles de resolver según el funcionamiento ordinario del sistema" ${ }^{28}$.

Una acentuada, aunque no exclusiva, monoproducción y la dependencia de los mercados internacionales marcó la región desde el inicio del ciclo hasta su prolongada decadencia. El dinamismo económico estuvo estrechamente vinculado al proceso de poblamiento e impactó directamente sobre el número de personas que habitaron las otrora deshabitadas pampas taltalinas, mientras que el reverso del proceso expuso a los trabajadores al despido y el abandono de la región, como sucedió recurrentemente frente a las crisis locales o internacionales.

Un buen ejemplo fue la aplicación de la ley de Derechos de Exportación del Salitre, promulgada el 1 de octubre de 1880, aparato legal que estaba influido por la realidad de Tarapacá e incluiría Antofagasta y Taltal, gravando con $\$ 1,60$ la producción de cada quintal de salitre. Solo se consideró que para las explotaciones más recientes ubicadas al sur del paralelo $24^{\circ}$ L.S., esta entraría en vigencia el 11 de septiembre de $1881^{29}$. Este impuesto provocó dos grandes problemas a la región, en tanto, disminuyeron los ingresos municipales que se hicieron notar al preparar el presupuesto anual en 1881, cuando las autoridades locales declararon que los ingresos municipales habían mermado como "consecuencia de la paralización de trabajos, y de la emigración de habitantes por esta causa" ${ }^{30}$. No solo preocupaba la cesantía y la

\footnotetext{
${ }^{24}$ Papadimitriou, Dimitri B. y Randall Wray, L. 1986. "Minsky's stabilizing an unstable economy: two decades later", en Minsky, Hyman. Stabilizing an unstable economy, New Haven, Yale University Press, (p. XXII).

${ }^{25}$ Minsky, Stabilizing an unstable economy..., p. 72.

${ }^{26}$ Idem.

27 Ibid., 315

${ }^{28}$ Rapoport y Brenta, "La crisis económica mundial: ¿el desenlace de cuarenta años...

${ }^{29}$ Godoy 0.2019. Milton. La puerta del desierto. Estado y región en Atacama. Taltal, 1850-1900, Santiago, Ed. Mutante, CNRS, Universidad de Tarapacá, pp. 219-221.

${ }^{30}$ Copiapó, 31 de diciembre de 1881. ANHMININT, Vol. 1050, s/f.
} 
disminución de los trabajadores, sino que la contracción económica global que afectaba a toda la comunidad local muy sensible a la actividad extractiva, al verse "reducidas las fuentes de producción salitrera, como resultado del impuesto fiscal que pesa sobre esta principal industria, la emigración de industriales se hizo sentir inmediatamente y de aquí la reducción de entradas en ese pueblo" ${ }^{31}$.

Los hechos acaecidos al inicio de la década de los ochenta marcaron el rumbo de lo que sucedería en el futuro. Las oficinas iniciaron los despidos y las autoridades les entregaron pasajes para que abandonaran la región o se atuvieran a las medidas coercitivas que las circunstancias "aconsejaban". ${ }^{32}$ Cuando la demanda de salitre aumentó se contrataron nuevos trabajadores y la pampa se repobló. La prensa resaltó esta movilidad, especialmente, durante el verano de 1898, cuando se destacaba la llegada de inmigrantes chilenos con sus familias a trabajar en Salta (Argentina), debido a "la crítica situación económica porque actualmente atraviesa Chile, es la causa principal que obliga a nuestros vecinos a buscar hospitalidad y trabajo" ${ }^{33}$. Algunos meses después, en el mismo periódico, un articulista escribía -con algún dejo de sorna- acerca del movimiento de los trabajadores salitreros despedidos de las faenas: "después de un breve descanso en las ciudades más populosas del territorio central, donde sirven de elemento perturbador, vuelven otra vez al norte, regresan después al sur y en tantas subidas y bajadas, no obtienen otro resultado que un conocimiento más o menos exacto del territorio del país" 34 .

\section{Economía regional y movimientos de población intercensales e intrarregionales}

En 1900, al analizar el ejercicio financiero de The Taltal Railway Company, Edmund Batten Forbes, Gerente General de la compañía informaba a sus accionistas en Londres acerca de la disminución en el transporte, indicando que "esta caída se debe en parte a la escasez de mano de obra en la pampa, también a la ausencia de veleros en la costa y, en parte, al aumento del precio del carbón" ${ }^{\prime 35}$. Estos factores, sumados a los ritmos de la economía, los conflictos internacionales, la política económica nacional, los precios del salitre, carbón y petróleo, entre otros, incidieron en que la producción y transporte salitrero en la región de Taltal estuvo marcada por periodos de inestabilidad.

La primera década del siglo XX en la región fue, esencialmente, de crecimiento económico, hasta el peack de 1914, mientras que la década de los veinte estuvo marcada por la

\footnotetext{
${ }^{31}$ Chañaral, octubre de 1882. ANHMININT, Vol. 1034, s/f.

${ }^{32}$ Al intendente de Atacama", Caldera, 9 enero de 1882, en ANHIAT, vol. 571, fs. 2.

${ }^{33}$ AHS, El Cívico. Salta, 13 de enero de 1898.

${ }^{34}$ AHS, El Cívico. Salta, 8 de marzo de 1898.

${ }^{35}$ Report of the Directors and Statement of Accounts. The Taltal Railway Company Limited, Londres, Ed. Waterloo and son Limited, 1900, p. 12. (En adelante RODSA)
} 
inestabilidad, con su caída abrupta en 1922. La segunda mitad de esta década anunció el quiebre final de la industria salitrera que, en términos de transporte, significó un tercio de los años de mayor solidez que hubo a inicio de siglo. Desde allí en adelante, aun con pequeñas recuperaciones, la industria salitrera estaba en fase terminal.

Desde 1875 a 1885, hubo un crecimiento de la población en la pampa y en el puerto, aumentando levemente en el decenio censal siguiente, aunque no existió un cambio sustancial, puesto que la población de 12.423 habitantes en 1895 había aumentado en 499 personas. Lo importante de este cambio es que el periodo intercensal tuvo variaciones en el movimiento intrarregional de la población, disminuyendo los habitantes de la comuna de Taltal en un $11,6 \%$, mientras que en la de Catalina aumentaba en un 30,1\%. Este crecimiento de los habitantes en la pampa perduró en el censo siguiente, aumentando en la pampa en un $158 \%$, mientras que el puerto lo hacía en un $73 \%$.

En términos rigurosos, el poblamiento respondía a que, desde 1884 , hubo un periodo de crecimiento exponencial en la producción y transporte de salitre, empinándose desde las 12.657 toneladas de aquel año a 160.683 en 1895 (ver gráfico $N^{\circ}$ 2). Este crecimiento enfrentó altibajos en el último lustro del siglo, descendiendo a 110.934 en 1900. La inestabilidad de la demanda provocó que el transporte, el año siguiente, aumentó en un $82,3 \%$, marcando un periodo de expansión que se tradujo en la época dorada de la industria salitrera en Taltal, aunque con periodos anuales de altibajos entre 1901 y 1907 . Aquel año el crecimiento inició una escalada que lo condujo al punto más alto del transporte salitrero al puerto, alcanzado las 319.861 toneladas en junio de 1914. Por cierto, el impacto social y económico en la región fue gravitante: aumentó la población, se instalaron bancos extranjeros, agencias, casas comerciales, consulados y el puerto bullía de actividad.

Desde 1914, hubo un periodo de contracción previo a la Primera Guerra Mundial, que expulsó población hacia el centro de Chile. Se informó al ministro del interior Rafael Orrego que los agentes de las compañías de vapores habían aceptado las órdenes de pasajes en tercera clase expedidas para movilizar hacia el centro del país a los trabajadores desocupados con sus familias. Para mantener la tranquilidad social y trasladar a más personas, se enviaron buques de guerra al Norte: el Blanco, a Antofagasta; el Esmeralda a Iquique; el O'Higgins a Antofagasta y el Lynch y Condell a Taltal. Los despidos gatillaron el interés por iniciar el estudio de un plan de obras públicas, saneamiento y regadío para Arica y se proyectó unir a Iquique con una vía longitudinal ${ }^{36}$.

En el caso de Taltal, las autoridades y empresarios frente al problema que les generaban los desempleados y sus familias que no alcanzaban a enviarse en barcos hacia el centro del país, optaban por trasladarlos a Copiapó, donde recibían boletos de tren para desplazarse más al sur.

\footnotetext{
${ }^{36}$ Santiago, 8 de agosto de 1914. Archivo Nacional Histórico, Ministerio del Interior (ANHMINT), Vol. 4365, s/f.
} 
Para dimensionar el problema, es posible señalar que en el mes de agosto 2.384 cesantes, más sus familias, arribaron a Copiapó, Chañaral, Vallenar y Freirina, manteniéndose el flujo en septiembre, pues como escribió una autoridad regional, "en el mes que va corrido sigue llegando gente" 37 . El proceso en el periodo fue similar: los trabajadores llegaban hasta Copiapó y solicitaban los boletos para desplazarse más al sur, los que eran entregados por la Intendencia de Atacama a un policía, quien los distribuía en la estación al abordar el tren longitudinal ${ }^{38}$.

En el primer año de la guerra el transporte desde la pampa disminuyó en un 61\%, porque no había demanda y -como informaron las autoridades del ferrocarril- "todo el nitrato producido permaneció en stock en el interior, ya que las bodegas portuarias estaban llenas y no se efectuaba ningún embarque" ${ }^{39}$.

Así, se inició un periodo de turbulencias económicas que se alternaban entre años de expansión en la explotación, producción y transporte, con años de repliegue y caída de la actividad. El último año de importante expansión fue 1918, cuando se bajaron al puerto 312.485 toneladas de salitre, para caer en un $57 \%$ al año siguiente, hasta su nivel más bajo del periodo en 1922, cuando se condujeron al puerto 69.056 toneladas. De hecho, el periodo 1917-1919 se caracterizó por una "sensación general de crisis y desencanto" en la sociedad chilena y significó un periodo de inestabilidad sociolaboral que después de sucesivas manifestaciones, entre ellas las "Marchas del hambre" 40 , en Santiago y la declaración de Estado de Sitio en varias provincias del país, se consolidó en 1924 con la "crisis integral", presionando el sistema al colapso institucional de ese periodo ${ }^{41}$.

Desde esta perspectiva la década de los veinte $-y$, tal vez, un poco antes- fue el anuncio del repliegue y caída de una actividad en retroceso, principalmente, debido al cierre de salitreras, periodos de producción menores, desmantelamiento o traslado a otras regiones, como en el caso de la oficina Britannia, llevada a Antofagasta en 1917 o la oficina Lilita, trasladada a Iquique en 1918.

La década de los veinte es definitoria en el proceso que enfrentaría la producción salitrera y la economía regional. En efecto, al inicio de ese periodo, entre los años 1920-1921 el transporte de salitre alcanzó 249.711 toneladas, para descender, al inicio de la década de los treinta a 49.150 toneladas en el lapso 1932-1933, disminuyendo en un $80.3 \%$. Un indicador de la situación de la población fue el aumento de ingresos del ferrocarril debido, según el gerente de

\footnotetext{
37 Jefe de la Oficina del Trabajo al Ministerio de Industria y Obras Públicas. Copiapó, 10 de septiembre de 1914. AHMRA, Intendencia de Atacama, Vol. 288, fs. 159.

${ }^{38}$ Copiapó, 20 de mayo de 1921. AHMRA, Intendencia de Atacama, Vol. 296, fs. 120.

${ }^{39}$ RODSA, 1915, p. 11.

${ }^{40}$ Alfredo Riquelme. 2001. Protesta y Soberanía Popular: Las Marchas del Hambre en Santiago de Chile 1918-1919, Pontificia Universidad Católica de Chile, Tesis para optar al Grado de Licenciado en Historia.

${ }^{41}$ Ortega, Luis. "La crisis de 1914-1924 y el sector fabril en Chile", Historia N 45/ II, Santiago, 2012, p. 454.
} 
la empresa, al "cierre de varias oficinas [que] explica el mayor número de pasajeros de segunda clase, ya que los obreros y sus familias han sido trasladados al puerto para ser enviados al sur" ${ }^{\prime 2}$.

Los cesantes fueron asistidos por las autoridades con cierta indolencia, provocando que en febrero de 1921 el ministro Pedro Aguirre Cerda escribiera al Gobernador de Taltal, autorizando el gasto de \$2.000 con cargo a su ministerio para alimentación de los despedidos y le conminaba a "hacer las gestiones con la mayor diligencia para aliviar situación" y obligar a que los empresarios cumplieran la ley, debido a que los "obreros cesantes se quejan de que usted no hace gestiones ante casas salitreras para que no despidan operarios sin darles desahucio y sean pagados pasajes de bajada al puerto" ${ }^{43}$.

Como solución, nuevamente, parte de los trabajadores despedidos fueron enviados a Copiapó, bajo la premisa de que los trabajadores "han venido desde el norte con motivo de la paralización de los trabajos de las salitreras y que vienen en busca de ocupación” ${ }^{44}$. En 1923, el gerente del ferrocarril justificaba la pérdida en ingresos por concepto de pasajes debido a que en el año anterior "se trajo un número considerable de trabajadores de las oficinas de nitratos que cerraron ${ }^{45}$.

Los altibajos persistieron en la década del treinta, acrecentándose la baja poblacional en el censo de 1940 , con una pérdida del $53.5 \%$ de la población de la comuna con respecto al de 1920. Estas dos décadas permiten visualizar un problema importante en términos de los trabajadores salitreros y la población de la pampa. Al comparar los censos de 1920 y 1930 es posible constatar que la fluctuación entre ambos momentos fue, desde la perspectiva del poblamiento, absolutamente negativa, debido a que las oficinas expulsaron 8.534 personas, es decir, el $45,6 \%$ de su población, periodo en el cual los habitantes de la comuna de Taltal disminuyeron en un 7,6\%., perdiendo 667 habitantes. El despoblamiento fue innegable y la población abandonó la región, pues no existe una definición numérica del movimiento intrarregional. A más abundar, si se considera en términos de la ubicación de los habitantes, entre 1920 y 1940, el despoblamiento en la pampa salitrera fue radical, pues la población total del interior disminuyó en un $81 \%$ y la del puerto aumentó en un $5,3 \%$. Obviamente, los demás trabajadores y sus familias abandonaron la región, sin retornar.

\footnotetext{
42 RODSA, 1921, p. 11.

43 Pedro Aguirre Cerda al gobernador de Taltal. Santiago, 2 febrero 1921. ANHMINT, vol. 5604, s/f.

${ }^{44}$ Copiapó, 27 de mayo de 1921. AHMRA, IATA, Vol. 296, fs. 131.

45 RODSA, 1923, p. 10.
} 
Mapa 1: División territorial del Departamento de Taltal.

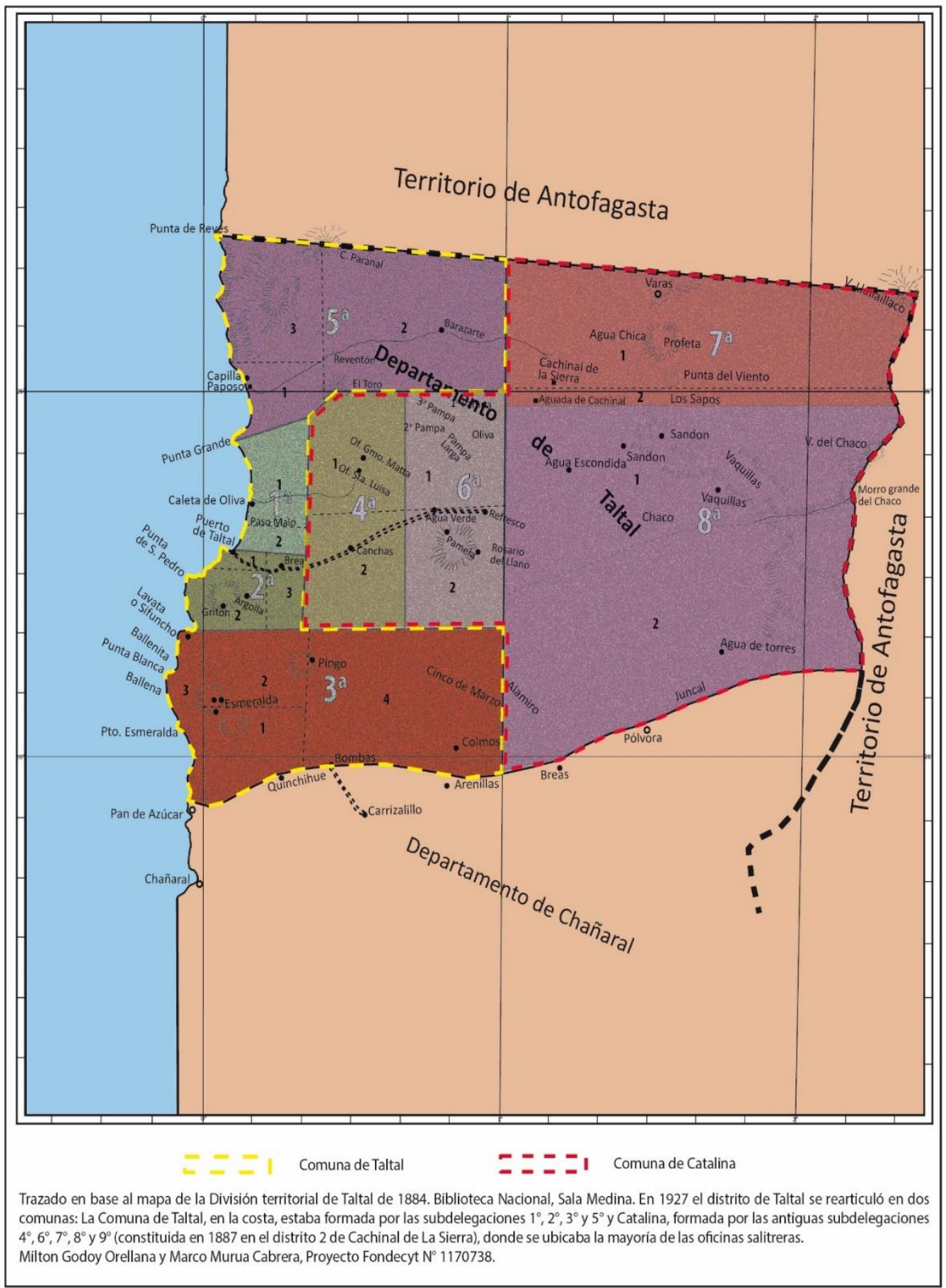


Este descenso en el número de habitantes fue un proceso concomitante al cierre de oficinas salitreras desde la década del veinte, proceso que fue intensificándose desde la crisis de 1929, cuando devino en radical e irreversible. Este fenómeno es constatable desde el año 1925, que marcó un hito con 276.397 toneladas conducidas al puerto. No obstante, a mediados de diciembre de 1925, se anunciaba el pronto cierre de la oficina Alemania, debido a que se había enterado la cuota de producción fijada por la Asociación Salitrera y forzosamente debía detener la producción y despedir alrededor de mil trabajadores. La prensa destacaba que "el traslado al sur de esta enorme masa de obreros significaría algo inoportuno en estos momentos en que en las regiones del centro y sur hay crisis absoluta de trabajo" ${ }^{46}$.

Los miedos de la comunidad eran premonitorios. La sensación de quiebre que vivían, era un gran problema que minaría el desarrollo futuro del poblado. Estas sensaciones se basaban en el cierre de un alto porcentaje de las oficinas que laboraban en la pampa taltalina. El caso más representativo fue la oficina Santa Luisa, una empresa que no paralizó sus funciones, manteniendo -aparte de periodos de cierre de algunos meses- su producción permanente en las crisis anteriores. Al respecto, la prensa escribía que "la noticia que se nos proporciona hoy, viene a darnos un dejo de nueva inquietud", porque, junto al cierre de la oficina Alemania, que exploraba nuevas tecnologías en frío, Santa Luisa, era la única que podía asegurar trabajo, en lo que la prensa definía como la "enorme debacle que se acentúa día a día, con caracteres verdaderamente alarmantes" ${ }^{\prime 7}$. Los miedos societales que reflejaba el periódico, se concretaban en la paralización de las oficinas Chile, Tricolor, Caupolicán, Delaware, Alemania y Moreno. La prensa insistía en la irresponsabilidad de los gobiernos del periodo, quienes, a su juicio, seguían "con la calma impasible llenando el país de seres desocupados; hombres de trabajo que no pedían limosna sino trabajo", sin hacer nada frente a la amenaza reiterada. Sin visos de grandilocuencia apocalíptica, el pueblo expresaba sus miedos:

"No solo es la masa obrera, esos seres que apenas les alcanzaba para medio comer, los que aquí se perjudican, sino todo, absolutamente todo el pueblo, el que paga las consecuencias de esta indolencia gubernativa, y, sin duda alguna, habrá llegado el momento de encontrarnos sitiados por el hambre.

¡Es ya tiempo que los Poderes Públicos se preocupen de estos graves problemas que afectan la vida de los habitantes de estas regiones tan censurablemente abandonadas...!" 48 .

Aunque algunas cifras variables demostraran cierta recuperación, sus miedos no fueron exacerbadas narrativas. El primer impacto fue que durante el año salitrero de 1927 el

\footnotetext{
46 “Paralización de la oficina Alemania. Se proporcionará trabajo en el norte a los cesantes”. BN, La Voz del Pueblo. Taltal, 16 de diciembre de 1925.

${ }^{47}$ BN, La Voz del Pueblo. Taltal, 6 de noviembre de 1926.

${ }^{48}$ BN, La Voz del Pueblo. Taltal, 6 de noviembre de 1926.
} 
transporte al puerto descendió en un $56 \%$ y a fin de la década, inclusive meses antes de las primeras manifestaciones de la crisis del jueves 24 de octubre de 1929, el cierre de las salitreras era una realidad. En el año salitrero de 1929-1930, el transporte y la producción estuvo en franca caída porque -como informó el gerente del ferrocarril- las oficinas Ghyzela, Lautaro, Ballena, Alberto Bascuñán, Esperanza, Flor de Chile, Tricolor, República, Moreno y Constancia, “permanecieron cerradas durante todo el año" ${ }^{49}$. En 1930, se sumaríam las oficinas Caupolicán, Chile y Alemania.

Esto fue irreversible y corrobora que el periodo post crisis de 1929, fue particularmente duro para la realidad económica y social de la región, propinándole el golpe final a una actividad que venía en franca decadencia. En la década de los treinta, continuó la pérdida poblacional del interior, provocándose un movimiento inversamente proporcional entre la pampa y el puerto, pues mientras en uno disminuía en el otro aumentaba en la misma proporción. Este movimiento intrarregional persistió de manera inversa en la década de los cuarenta, cuando hubo una pequeña recuperación de la producción y transporte de salitre, para volver al movimiento revertirse en la década de los cincuenta cuando se volvió a despoblar la pampa.

En términos rigurosos, en junio de 1930, se bajaron desde la pampa 160.300 toneladas, descendiendo en un 69,3\% en 1933. Esta disminución se debió a que entre 1931 y 1932, The Lautaro Nitrate Company, paralizó las oficinas Alberto Bascuñán, Ballena, Lautaro y Santa Luisa, que funcionó parcialmente. ${ }^{50} \mathrm{~A}$ estas se sumaron Chile, Flor de Chile, y Tricolor, quedando en funcionamiento en 1933 solo Santa Luisa. La crisis dejó miles de cesantes en el puerto, quienes fueron "remitidos" hacia el sur con sus respectivas familias, como informaba el gobernador en su memoria trimestral:

"han alcanzado a una suma superior a cinco mil quinientas personas, todas las cuales han sido embarcadas en mui buenas condiciones, sin que se haya producido ningún accidente y sin que haya habido ningún reclamo. Quedan en el puerto alrededor de cien cesantes del personal que trabajaba en caminos y se está gestionando su envío al sur por cuenta del Gobierno, asunto que debe quedar resuelto en estos días" ${ }^{\prime 1}$.

El tema se complicó con el cierre de la oficina Alemania, cuya gerencia en Valparaíso ordenó el despido de 400 trabajadores, que junto a sus familias debían abandonar la oficina y trasladarse al sur, sumando alrededor de 1.000 personas $^{52}$. Dos días después, la autoridad

\footnotetext{
${ }^{49}$ RODSA 1930, p. 10

50 Juan Sánchez, administrador de las oficinas paralizadas de The Lautaro Nitrate Company. Santa Luisa, 3 de agosto de 1932. AHUCN. Oficina Santa Luisa, caja N²4, s/f.

${ }^{51}$ Oscar Moena, Memoria trimestral de la Gobernación. Taltal, 31 de diciembre de 1930, AHNIANT, Vol. 80, № 926, $\mathrm{s} / \mathrm{f}$.

52 Gobernador Oscar Moena al Intendente. Taltal, 10 de enero de 1931, AHNIANT, Vol. 81, º 36, s/f.
} 
señalaba que había 440 nuevos obreros cesantes, a esta se sumó el cierre de la oficina Caupolicán que envió al sur 300 cesantes en tren y 1.600 en vapores, ${ }^{53}$ aumentando la merma poblacional en alrededor de 6.500 personas en menos de un mes. La cifra anterior, frisaba el $35 \%$ de los 18.257 habitantes que consignó el censo de 1930. Las palabras del gobernador fueron categóricas "la crisis en general en el departamento, y muy especialmente la del comercio, se hace cada día más intensa" ${ }^{54}$.

Gráfico 1. Población del Departamento y Comunas de Taltal, 1875-1960

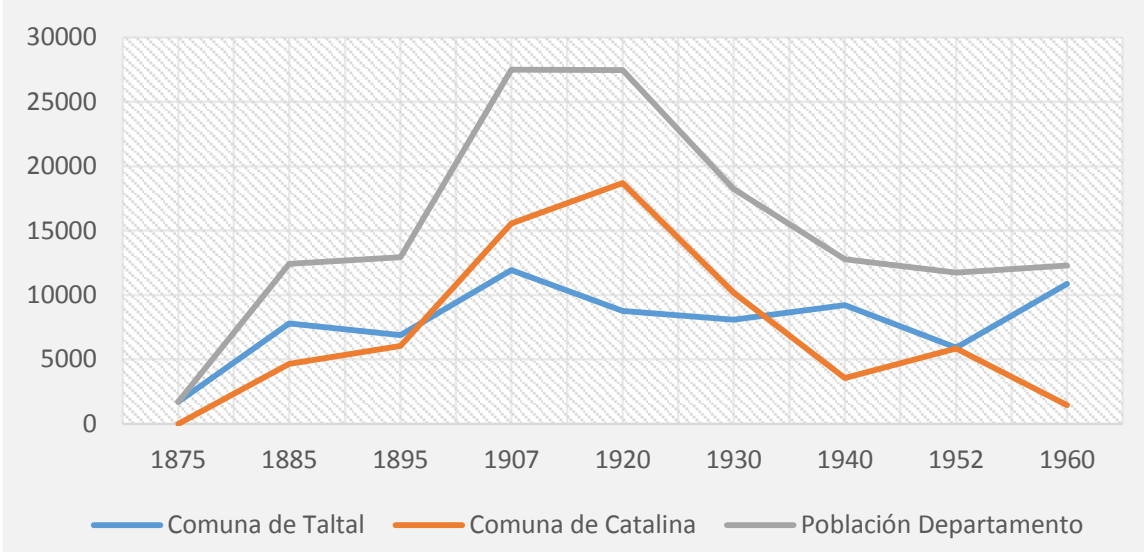

Fuente: elaboración propia a partir de revisión de Instituto Nacional de Estadísticas de Chile, Censos de Población años respectivos.

Gráfico 2. Producción y transporte de salitre, 1930-1954

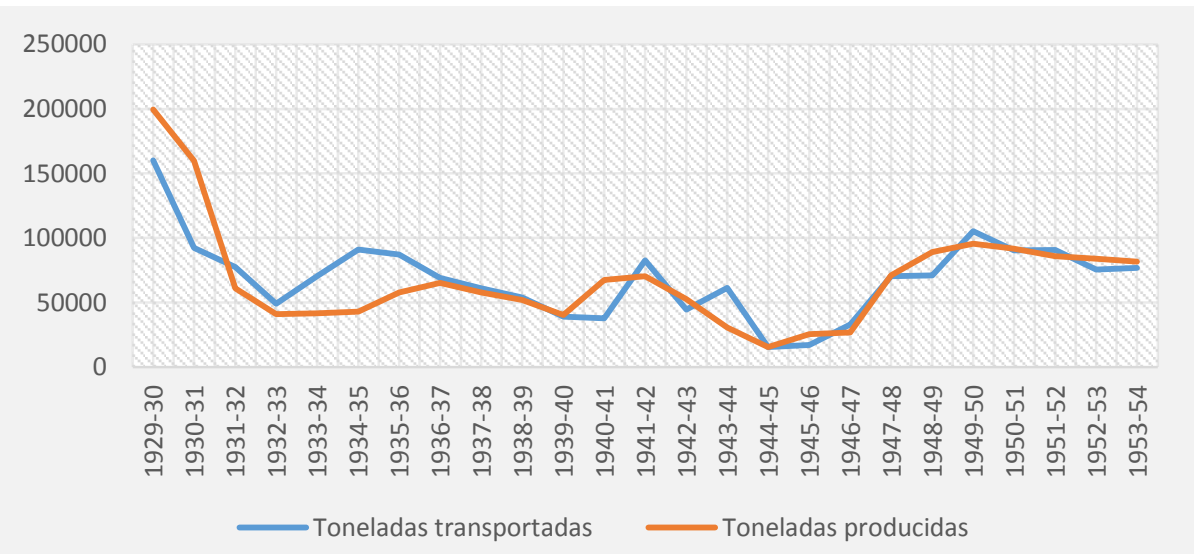

Fuente: elaboración propia a partir de Report of the director and statement of accounts. The Taltal Railway Company Limited.

\footnotetext{
${ }^{53}$ W.H. Pollock, Agente portuario. Taltal, 12 de noviembre de 1930. AHUCN. Oficina Santa Luisa, caja $N^{\circ} 3, \mathrm{~s} / \mathrm{f}$.

${ }^{54}$ Gobernador Oscar Moena al Intendente. Taltal, 12 de enero de 1931, AHNIANT, Vol. 81, N 51, s/f.
} 
Tabla 1. Funcionamiento de salitreras en Taltal, 1910-1955

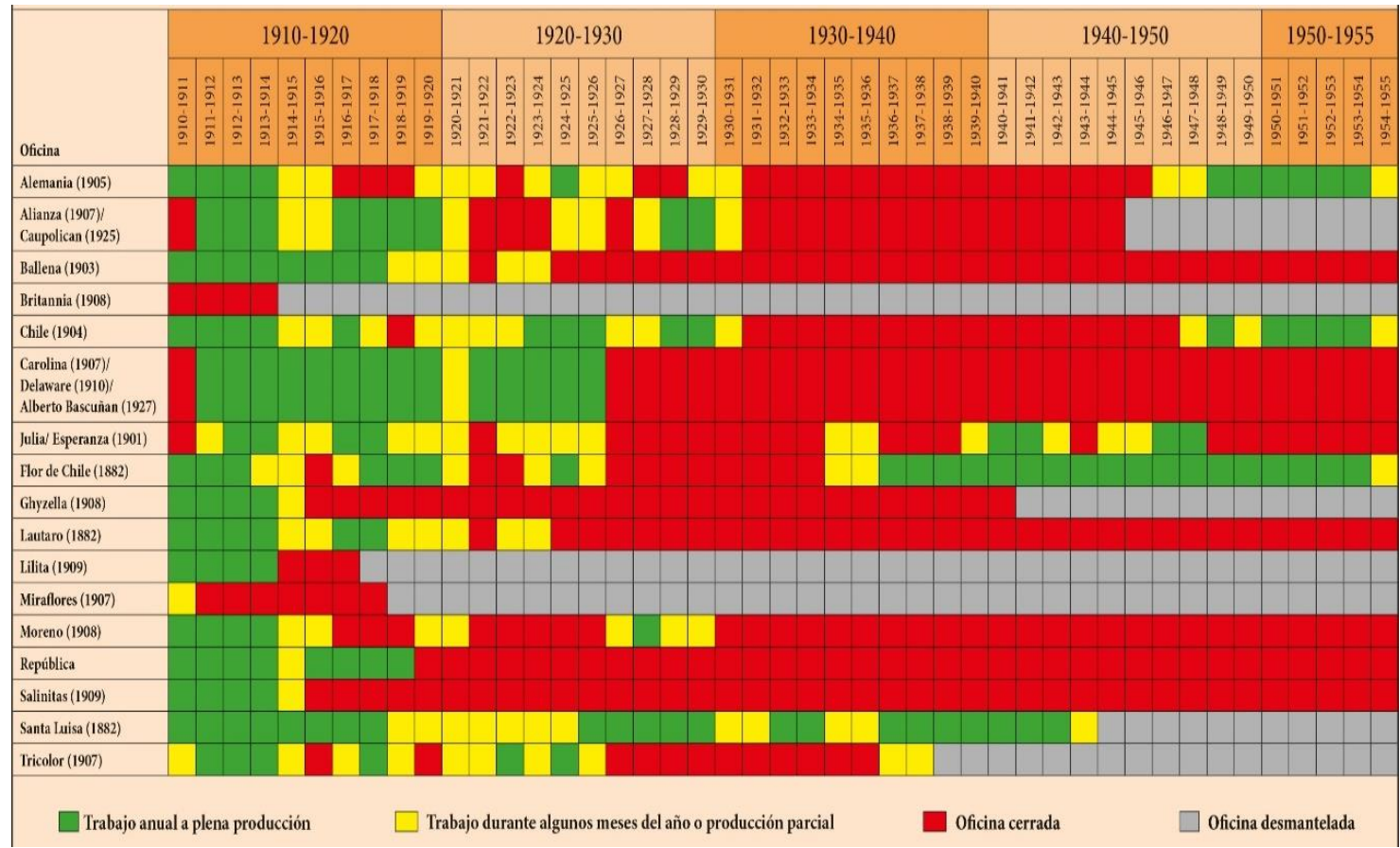

Fuente: elaboración propia a partir de revisión de: Report of the director and statement of accounts. The Taltal Railway Company Limited. Ed. Waterloo and son Limited, Londres (años respectivos).

Para graficar la situación global de la producción salitrera en la región es necesario analizar la tabla $\mathrm{N}^{\circ} 1$, donde se representan las oficinas funcionando, cerradas y desmanteladas entre 1910 y 1955 . Un análisis de estos datos permite visualizar la paulatina merma de oficinas en funcionamiento desde el inicio de la década del veinte en la que se suscitaron las crisis de 19211922 y 1925-1926, ambas con un importante impacto -como antes discutía- en la población de la pampa. La década del treinta fue el escenario de una abrupta disminución de las oficinas laborando, quedando solo Moreno, que cerró en 1930; Alianza, que produjo parcialmente y cerró en 1931; Alemania, trabajó a media capacidad durante 1931; Chile, produjo a su mayor capacidad en 1930 y a mediana capacidad en 1931, permaneciendo inactiva el resto de la década; Esperanza, a media capacidad durante los años 1935 y 1936, 1939; Flor de Chile, lo hizo a media capacidad durante 1935 y 1936, recuperando su total capacidad en 1937; Tricolor, que produjo parcialmente durante los años 1937 y 1938. Finalmente, Santa Luisa, fue la única oficina que trabajó permanentemente, reduciendo su capacidad productiva solo en los años 1935 y 1936.

En esta misma tabla es posible apreciar que en la década de los cuarenta Alemania, trabajó desde 1947 a 1948 con parte de su capacidad, desde allí lo hizo a total capacidad productiva, 
para descender en 1955 a media producción. La oficina Chile reinició en 1948 su producción parcialmente, aumentando a plena capacidad en 1949, bajar su producción en 1950, recuperándose el año siguiente a plena actividad hasta 1954 y bajar su producción a la mitad. En este año trabajaron solo tres oficinas a media capacidad y Flor de Chile, fue la única que trabajó sin interrupciones entre 1937 y 1954, para descender a media capacidad en 1955.

Un asunto pendiente es el destino de los trabajadores y sus familias que eran expulsados de Taltal. Se supone que fueron reabsorbidos por las salitreras de Tarapacá y Antofagasta, aunque el movimiento interregional de la población, como lo demuestran las fuentes, era hacia las provincias del centro y sur del país y pocos permanecían a la espera de ser reabsorbidos en otra fuente de trabajo. Cuando lo hacían, era en los puertos, buscando la ayuda de las autoridades para trasladarse nuevamente a las oficinas.

En julio de 1922, el gobernador de Taltal solicitó ayuda al Intendente de Antofagasta, frente a la negativa de algunos empresarios salitreros de financiar los pasajes de los cesantes que quería retornar a las salitreras. El intendente lo autorizó "para contratar pasajes a la pampa para obreros cesantes", recomendándole, "proceder con mucho tino y asegurándose en lo posible de que obreros tengan trabajo en el interior al trasladarse a fin de evitar que en pocos días más tengamos que pagar nuevamente pasajes para bajarlos a Antofagasta" ${ }^{55}$.

El móvil principal era eliminar el problema de los despedidos aglomerados en los puertos. De hecho, cuando la recuperación se verificaba, el Ministerio del Interior ofició a las intendencias y gobernaciones de la región salitrera, para que cesaran de expulsar personas fuera de la región, porque "algunas oficinas están solicitando trabajadores, sírvase US. no enviar en lo sucesivo obreros cesantes para el sur. Entrada del invierno, que en esta zona es riguroso, aconseja también dejar a esa gente allá" 56 .

Lo acontecido en 1926-1927 es un ejemplo esclarecedor. Resultado de la crisis de esos años, abandonaron la región 6.645 personas de los cuales el $45.9 \%$ eran trabajadores despedidos, el $21,5 \%$ mujeres y un $32,6 \%$ niños ${ }^{57}$. Esta gran cantidad de población significó una disminución del 35,5\% de los habitantes de la comuna de Catalina, donde se ubicaban las salitreras más importantes de la región.

La merma poblacional en la década del veinte fue abismante y no se detuvo al interior de la región con el fin de la crisis de 1925-1926, sino que se profundizó, significando una disminución de la población del $57,2 \%$ en el censo de 1930 con respecto al 1920.

En 1930, el destino de los trabajadores fueron las provincias al sur de Taltal. De hecho, en los oficios enviados entre las autoridades de The Lautaro Nitrate Company, se titulaban

\footnotetext{
${ }^{55}$ Taltal, 1 de julio dem1922. ANHMININT Vol. 5818.

${ }^{56}$ Santiago, 28 de abril de 1922, ANHMINT, vol. 5812, s/f.

${ }^{57}$ Boletín de la Oficina del Trabajo. Santiago, Ed. Dirección del Ministerio, 1927, p17.
} 
"Devolución de obreros al sur" y en uno de ellos se consignaba que de 115 personas devueltas 32 iban a la provincia de Atacama y 83 lo hacían a la de Coquimbo ${ }^{58}$. Al igual que los 1.900 enviados antes, ninguna persona se fue a otra salitrera.

La pérdida poblacional persistió durante las décadas restantes, aunque producto de la inestabilidad poblacional, característica de la industria salitrera, tuvo una leve recuperación debido a un aumento de la producción entre 1947 y 1950. En esta transitoria bonanza, se transportaron 105.308 toneladas al puerto y en 1951 se inició un nuevo descenso, que en el año salitrero de 1954 significó una disminución del 27\%. Este hecho impactó en que la población en 1952 se recuperara, alcanzando un 31\% de la que habitó la pampa en el momento de mayor presencia poblacional. Esta recuperación duró un breve periodo de tiempo, debido a que en 1960 volvió a descender a un 7,7\%, de la población que hubo en 1920, para no recuperarse en el transcurso del siglo.

\section{Gráfico 3. Destino de trabajadores y familias devueltos al sur durante la crisis, Taltal, 1926-1927.}

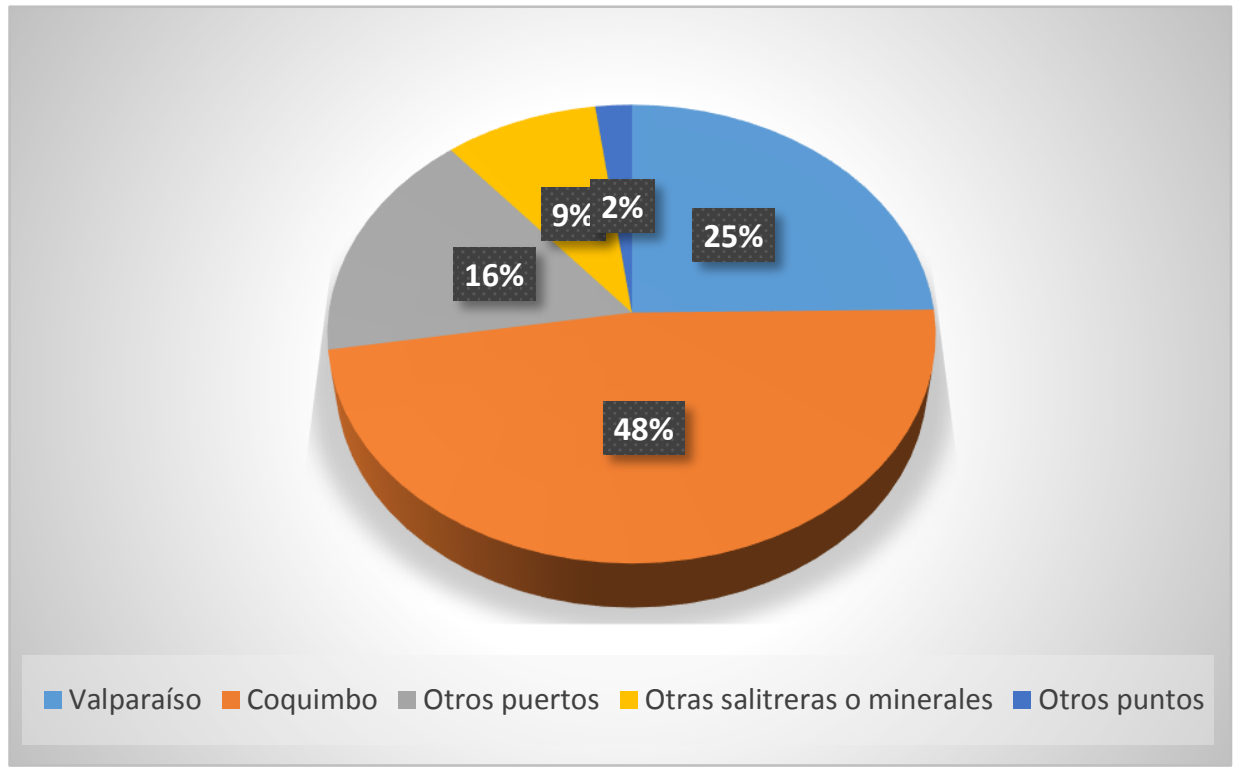

Fuente: elaboración propia a partir de Boletín de la Oficina del Trabajo, 1927.

\section{La fiebre del desarme ${ }^{59}$}

Las páginas de la prensa local de la década de los cuarenta están saturadas de alusiones a la situación salitrera de la región. El conjunto de opiniones acerca de la realidad enfrentada se puede sintetizar en un artículo de 1944 que, descarnado, resumía la situación: “lentamente han

\footnotetext{
${ }^{58}$ The Lautaro Nitrate Company. Talta, 12 de noviembre de 1932. AHUCN. Oficio 24/, Bienestar, caja N 3, s/f.

${ }^{59}$ BN, El Pueblo. Taltal, 18 de febrero de 1944.
} 
ido apagando sus fuegos las oficinas salitreras. La fiebre del desarme, nuevo filón de fácil fortuna, ha transformado la pampa en un cementerio de elefantes". Categórico, anunciaba lo que realmente sucedería algunos años después "Este es el fin" 60 .

En efecto, al inicio de la década de los cuarenta, se llegó al punto más bajo de casi medio siglo de explotación, alcanzando en 1944 solo 15.643 toneladas, una cantidad similar a las 14.556 transportadas en 1889 , cuando la industria salitrera regional estaba en su inicio.

El caso de Taltal se inscribía en un fenómeno más amplio que afectó a los puertos de Iquique a Taltal. La prensa describía la situación como irreversible "es bien triste escuchar la desolada descripción que hacen de la vida los pobladores de la costa", quienes, según El Pueblo, solo pensaban "en el éxodo para escapar a las duras estrecheces que soportan en aquellos en otros tiempos prósperos lugares". La actividad febril de las pampas salitreras se había convertido en una región abandonada y sus habitantes estaban "a la espera del barco que les ha de llevar a Coquimbo o Talcahuano en busca de algún medio para ganarse el pan. Nos parece, sino que viven en la antesala de otra crisis mucho más pavorosa que la de 1920 a $1928^{\prime \prime 61}$.

El primer quinquenio de la década presentaba el escenario menos auspicioso vivido en la historia salitrera de la región y marcaba el principio de la caída final -como señaló un periódico años después- hasta 1945 “la decadencia de este puerto era notoria" ${ }^{62}$. Numerosas salitreras eran cerradas y desmanteladas, emergiendo en la vida económica local un tipo de empresarios que se transformaron en los panteoneros del periodo salitrero, dedicándose a desmantelar oficinas salitreras. En este periodo apareció Farandatu y Cía., una de las primeras empresas dedicada al rubro, quienes adquirían maquinarias y construcciones, para desguazarlas y vender los componentes, principalmente metales y madera. En 1941 se inició el desmantelamiento de la oficina Ghiyzella y en 1945 el de Santa Luisa. Esta última, desde 1944 estaba en producción parcial e inició un proceso de despido de sus trabajadores que, como ejemplo, entre el lunes 28 de febrero y el martes 7 de marzo, acorde con la nómina de "despachados al sur" ${ }^{63}$, se embarcaron 198 trabajadores, indicando que el cierre era inminente. Como señaló la prensa:

“Cesarán así las actividades de la principal fuente de bienestar y progreso económico con que cuenta el Departamento de Taltal, que, a causa de esta contingencia, deberá afrontar un problema serio y de difícil solución. La paralización de las labores de la Oficina Salitrera de nuestra referencia, como es obvio, perjudicará en primer término, a los obreros y empleados que quedarán sin trabajo, así como también a sus respectivas familias. [...]

\footnotetext{
${ }^{60}$ BN, El Pueblo. Taltal, 18 de febrero de 1944.

${ }^{61}$ BN, El Pueblo. "Los puertos del norte". Taltal, 10 de marzo de 1944.

62 BN, La Voz del Pueblo. Taltal, 14 de junio de 1967.

63 "Obreros despachados al sur" Santa Luisa, 28 de marzo de 1944. AHUCN, Oficina Santa Luisa, caja N 18, s/f.
} 
El comercio de Taltal vive y se desarrolla gracias a la demanda de artículos alimenticios, ropas, útiles caseros, etc., del personal de Santa Luisa. Numerosas industrias también se sostienen por obra de las mismas circunstancias. Pues bien, la desaparición del poder adquisitivo que coincidirá con la cesación de los trabajos amenaza arruinar la industria y el comercio. $^{64}$

Paralelamente, al cierre y desmantelamiento, se produjo el repliegue de las líneas férreas que conducían a estas oficinas, procediendo al levantamiento de los ramales, sumando un elemento negativo a la economía regional. La empresa del ferrocarril había enfrentado periodos de ingresos muy bajos, con escasa rentabilidad y una disminución notable del transporte salitrero -que durante todo su ejercicio fluctuó entre el 96 y el $98 \%$ de sus ingresosque estaba lejos de las 319.861 toneladas transportadas en 1914, representando en 1945 un $4,9 \%$ de esa cifra y, un año antes de su venta, significó un $24 \%$ de ese mismo monto.

En 1955, después de sucesivas pérdidas e intentos de venta al Estado de Chile, el ferrocarril fue vendido a Rumié Hijos S.A., quien iniciaría un paulatino desmantelamiento, vendiéndolo por partes. En Inglaterra, se envió una circular a los accionistas convocándoles a una Junta General Extraordinaria a efectuarse el 9 de septiembre de 1955, donde fue aprobada la venta de los activos fijos, material rodante, equipos, bodegas y propiedades de la compañía en Chile. $^{65}$

\section{Conclusión}

La conducta oscilante de la población tuvo explicaciones multifactoriales. Entre otros, fue producto de las crisis económicas y de los intereses de los empresarios, quienes usaron el mecanismo del enganche como regulador de los precios del trabajo y de las conductas políticas de los trabajadores. En ambos casos, cuando uno u otro eran adversos a los intereses de los empresarios, se procedía al despido, contratándose mano de obra proveída por los enganchadores desde el centro y sur del país o de otras oficinas salitreras. El móvil de atracción fue mejores niveles salariales, cuya mejoría atraía desde otra salitrera o desde el sur de la región.

En el proceso de poblamiento y despoblamiento las crisis jugaron un papel esencial, principalmente desde la década de los veinte, con la crisis de 1929 que, para Taltal, desde la década de los treinta, fue el inicio de una situación terminal con el cierre de numerosas salitreras y el consecuente levantamiento de la línea férrea.

Como se planteaba al inicio de este trabajo, hubo, a lo menos, tres grandes periodos de movilidad poblacional en el norte de Chile. El primero, fue el traslado de pobladores,

\footnotetext{
${ }^{64}$ BN, El Pueblo. Taltal, 24 de febrero de 1944.

65 RODSA, 1955, p. 2-3.
} 
principalmente, hacia el Norte Chico, durante su periodo de expansión cuproargentífero, entre 1840 y 1880 . En segundo lugar, el movimiento de parte de estas poblaciones a las que se sumaron extranjeros de los países aledaños y de ultramar, configuraron el poblamiento correspondiente al periodo salitrero de mayor expansión, suscitado entre 1880 y 1930 . En el periodo hubo un mayor poblamiento de la región salitrera. En el caso de Taltal, este movimiento se inició con baqueanos y mineros que desde 1870 arribaron desde el vecino Copiapó y formaron la base de la futura población, a los que se sumarían contingentes de diversos orígenes. En esta región el máximo poblacional y económico se produjo entre los años 1900 y 1920, manteniéndose cuando hubo expansión de las explotaciones y un importante flujo en el movimiento salitrero y de otros minerales, complejizando la vida social y haciendo del puerto un espacio bullente en actividad. La década del veinte marcó los primeros ritmos de la despoblación que se avecinaba y que en 1930 redujo la población a la mitad y persistió la pérdida poblacional, principalmente en la pampa, al ritmo de la caída de la industria salitrera. El correlato de la caída de la producción de nitrato fue el cierre y desmantelamiento de la capacidad instalada de las empresas productoras, la disminución de la población en la pampa y el repliegue de las líneas férreas, las que eran levantadas y vendidas por partes. Así, fue posible observar que de las 17 oficinas que operaron en las primeras décadas del siglo XX, al inicio de la década de los treinta lo hacían seis, que trabajaron esporádicamente. La década siguiente el número se redujo a cuatro y a mediados del siglo, siete oficinas habían sido totalmente desmanteladas y solo operaban tres, aunque a mediana capacidad y con intervalos. En los censos posteriores se consolidó la merma poblacional que, en 1952, representaba un descenso del $57,3 \%$ de los habitantes de la comuna y en la pampa llevó al despoblamiento paulatino, hasta representar un $7,7 \%$ de los habitantes en su momento de mayor expansión. A estas variables se sumó un fuerte movimiento intrarregional de la población, la que bajaba al puerto esperando un mejoramiento de las condiciones. No obstante, el grueso de los pobladores abandonó la región en las tres crisis de los años veinte.

Así, el caso de Taltal, demuestra con claridad que el problema de la expulsión de mano de obra por efecto de la caída de la industria salitrera fue complejo y que el análisis cualitativo de los documentos es imprescindible. Sin esta perspectiva, un investigador descuidado, que solo fundamente los problemas sociales en la perspectiva numérica, acabará como el borracho apoyado en el poste que describía Churchill, a quien los datos estadísticos sostienen, pero no iluminan, convirtiéndose en un ejercicio intelectual que, como en el caso de la autofagia del uróboros, termina comiendo su propia cola. 


\section{Fuentes y bibliografía}

\section{Fuentes}

Archivo Nacional Histórico.

- Fondo Ministerio del Interior (ANHMININT).

- Fondo intendencia de Atacama (ANHIAT).

- Fondo Intendencia de Antofagasta.

Archivo Histórico Museo Regional de Atacama (AHMRA).

- Fondo Intendencia de Atacama.

Archivo Histórico Universidad Católica del Norte.

- Fondo Lautaro Nitrate Company. Archives of Guildhall Library, Londres

- Report of the Directors and Statement of Accounts. The Taltal Railway Company Limited, Londres, Ed. Waterloo and son Limited

Hemeroteca de la Biblioteca Nacional (BN)

- La Voz del Obrero, Taltal (1908, 1926, 1967)

- El Pueblo, Copiapó (1852)

- La Voz del Pueblo, Taltal $(1908,1926,1967)$

- El Pueblo, Taltal (1944)

Archivo Histórico de Salta (AHS)

- El Cívico, Salta (1898)

\section{Bibliografía}

Artaza, P. 2018. "Los cantones salitreros como espacio de tránsito y circulación. Tarapacá durante el ciclo de expansión del salitre", en Revista Chilena de Antropología 37/1, Santiago, pp. 164-182.

Artaza, P. 2016. “El reverso del bienestar. La creación del departamento de bienestar social y el reforzamiento del control social en el norte grande a principios de los años 20", en Estudios Atacameños, $\mathrm{N}^{\circ}$ 52, San Pedro de Atacama, p.49-68.

Artaza, P. 2015. "De lo social a lo político en el movimiento social salitrero: el caso de la mancomunal de obreros de Iquique, 1900-1909", en Atenea N509, Concepción, pp.139-158.

Bensimon, F. 2017. Les sentiers de l'ouvrier. Paris, Ed. de la Sorbonne, pp. 5-21.

Bensimon, F. 2011. "British workers in France, 1815-1848", en Past and Present 213, Oxford, pp. 147189.

Boletín de las leyes y decretos de Chile, Vol. 54, Santiago, Imp. Nacional, 1887, p. 880.

Carrasco, A. 2014. "Remolinos de la pampa. Industria salitrera y movimientos de mujeres (1910-1930)", en Estudios atacameños $N^{\circ}$ 48, San Pedro de Atacama, pp. 157-174. 
Decreto con Fuerza de Ley 8583. Santiago, 30 de diciembre de 1927. www.leychile.cl/N?i=19463\&f=1928-02-01\&p=

Donoso, C. 2018. "Los albores de la industria salitrera en Tarapacá", en Chungará vol.50/3, Arica, pp. 459470.

Donoso, C. 2014. “El ocaso de la dependencia salitrera (1914-1926)”, en Diálogo Andino N45, Arica, pp. 97-118;

Donoso, C. 2014. "Nacionalizar el salitre: debates iniciales sobre el control fiscal de la industria (Chile, 1880-1916)", en Chungará, vol.46/1, Arica, pp.115-130.

Galaz-Mandakovic, D. 2018. "De Guggenheim a Ponce. Sistema técnico, capitalismo y familias en el extenso ciclo de los nitratos en El Toco y Tocopilla (1924-2015)", en Revista Chilena de Antropología $\mathrm{N}^{\circ} 37$, Santiago, pp. 108-130.

Galindo de Ugarte, M. 1991. Constituciones bolivianas comparadas, 1826-1967, La Paz, Ed. Los Amigos del Libro, p. 583.

Godoy, M. 2019. "Configuración estatal y económico-social de un espacio productivo minero en Chile: Taltal, 1870-1930", en Estudios Atacameños N 62, San Pedro de Atacama, pp. 163-180.

Godoy, M. 2019. “Llamado a un fabuloso porvenir. Explotaciones auríferas y poblamiento en el desierto de Atacama: El mineral de El Guanaco y la placilla de Aguada de Cachinal, 1880-1930", en Cuadernos de Historia $\mathrm{N}^{\circ}$ 51, Santiago, pp. 9-31.

Godoy, M. 2018. La puerta del desierto: Estado y región en Atacama Taltal, 1850-1900, Santiago, Ed. Mutante - Universidad de Tarapacá - LIA Mines, CNRS.

Godoy, M. 2016. “Los prolegómenos de una crisis episódica: El cantón de Taltal y la ley de impuesto a la producción salitrera, 1873-1883”, en Historia vol. 2, Santiago, pp. 455-486.

Godoy, M. 2015. "Las placillas del desierto. Construcción de espacio urbano en el despoblado de Atacama. Bolivia y Chile, 1870-1900", en Amérique Latine Histoire et Mémoire. Les Cahiers ALHIM, 29, Paris, URL: http://alhim. revues.org/5183.

González, S. 2018. "Las primeras estacas del reino salitrero de John Thomas North. El origen del mito", en Cuadernos de Historia $N^{\circ}$ 49, Santiago, pp.7-36.

González, S. 2009. "La presencia boliviana en la sociedad del salitre y la nueva definición de la frontera: auge y caída de una dinámica transfronteriza (Tarapacá 1880-1930)", en Chungará, vol.41/1, Arica, pp. 71-81.

González, S. 2013. La Sociedad del Salitre, Protagonistas, migraciones, cultura urbana y espacios públicos 1870-1940. Santiago, Ril Editores.

González, S., Calderón, R. y Artaza, P. 2016. “El fin del ciclo de expansión del salitre en Chile: la inflexión de 1919 como crisis estructural”, en Revista de Historia Industrial, Vol. 25, № 65, Barcelona, pp. 83110.

González, S. y Artaza, P. 2015. “Cateando la palabra: la construcción de nuevos archivos sobre la sociedad del salitre", en Diálogo Andino N46, Arica, pp. 55-70. 
González, J. 2018. "La Compañía de Salitres de Antofagasta, Chile. El desafío de su modernización empresarial e innovación estratégica", en Estudios Atacameños $N^{\circ} 60$, San Pedro de Atacama, pp. 133-159.

González, J., Lufin, M. y Galeno, C. 2017. “Mujeres latinoamericanas en el mercado laboral de Antofagasta durante el ciclo salitrero, 1880-1930", en Estudios atacameños N54, San Pedro de Atacama, pp. 153178.

González, J., Lufin, M. y Galeno, C. 2014. "Británicos en la región de Antofagasta. Los negocios concomitantes con la minería del desierto de atacama y sus redes sociales (1880-1930)", en Estudios Atacameños $\mathrm{N}^{\circ}$ 48, San Pedro de Atacama.

Guerassimoff, E. e Issiaka, M. 2015. Le travail colonial. Engagés et autres mains - d'oeuvre migrantes dans les empires, 1850 - 1950, Paris, Ed. Riveneuve.

Hobsbawm, E. 1951. "The tramping artisan", en The Economic History Review, New Series, Vol. 3, №. 3, New Jersey, pp. 299.

Kalazich, F. 2018. "Para estudiar la prostitución en las pampas salitreras. Apuntes desde los estudios subalternos y la arqueología industrial”, en Revista Chilena Antropología N 37, Santiago, pp. 131142.

Minsky, H. 1986. Stabilizing an unstable economy, New Haven, Yale University Press, p. XXII.

Monteon, M. 1979. "The Enganche in the Chilean Nitrate Sector, 1880-1930", en Latin American Perspectives, Vol. 6, №. 3, Riverside, p. 68.

Moulier-Boutang, Y. 2006. De la esclavitud al trabajo asalariado. Economía histórica del trabajo asalariado embridado. Madrid, Akal, p. 907.

Ortega, Luis. 2012. "La crisis de 1914-1924 y el sector fabril en Chile”, en Historia N 45/ II, Santiago, p. 454.

Papadimitriou, D. y Randall, L. 1986. "Minsky's stabilizing an unstable economy: two decades later", en Minsky, Hyman. Stabilizing an unstable economy, New Haven, Yale University Press, (p. XXII).

Rapoport, M. y Brenta, N. 2010. “La crisis económica mundial: ¿el desenlace de cuarenta años de inestabilidad?", en Revista Problemas del Desarrollo, 163/41, Ciudad de México, p. 9.

Reinhart, C. y Rogoff, K. 2011. Esta vez es distinto: ocho siglos de necedad financiera. México, Ed. FCE.

Richard, N. y Hernández, C. 2018. "Las alambradas en la Puna de Atacama: alambre, desierto y capitalismo", en Revista Chilena de Antropología, N³7, Santiago, pp. 83-107.

Riquelme, A. 2001. Protesta y Soberanía Popular: Las Marchas del Hambre en Santiago de Chile 19181919, Pontificia Universidad Católica de Chile, Tesis para optar al Grado de Licenciado en Historia.

Rivero, R., Navarrete, J., Órdenes, C. y Llorca, M. 2019. “The Demographic Consequences of the End of Chile's Nitrate Boom, c.1907-1940", en Bulletin of Latin American Research, Society for Latin American Studies, vol. 37, Reino Unido, p. 2.

Zamagni, V. 2011. Historia Económica de la Europa contemporánea, Barcelona, Crítica, p. 93. 